\title{
PERSPECTIVAS PARA UM NOVO PRODUTO ALIMENTÍCIO A BASE DE ÓLEO EXTRAÍdO DO FRUTO DA MACAÚBA (Acrocomia aculeata (Jacq.) Lodd. ex Mart)
}

\author{
P. P. VALÉRIO ${ }^{1}$, S. C. GRANDE ${ }^{1}$, M. H. C. DE ANDRADE ${ }^{1}$, E. C. CREN ${ }^{1}$ \\ ${ }^{1}$ Universidade Federal de Minas Gerais, Departamento de Engenharia Química \\ E-mail para contato: pedropratesvalerio@ hotmail.com
}

\begin{abstract}
RESUMO - Visando fortalecer e aperfeiçoar ações para a implantação da cultura Acrocomia aculeata (Jacq.) Lodd. ex Mart no cenário do agronegócio nacional, o presente trabalho vislumbra o aproveitamento dos óleos extraídos dos frutos da Macaúba como matérias-primas com valor agregado para a produção de alimentos. O trabalho apresenta uma revisão bibliográfica que contempla propriedades físicoquímicas e características de qualidade de óleos vegetais produzidos com finalidade alimentícia - dentre os quais os extraídos da oliveira (Olea europaea) e do dendê (Elaeis guineensis Jacq). Descrições de regulamentos técnicos, normas e metodologias preconizadas em órgãos e institutos nacionais e internacionais estão incluídos, contribuindo com a definição de parâmetros de processamento da Macaúba, tendo em vista a preservação de características nutricionais e funcionais naturais da oleaginosa. Finalmente, com base nas informações levantadas, o trabalho destaca o uso potencial dos óleos extraídos dos frutos da palmeira na elaboração de um novo produto alimentício, óleo de mesa, com apelos especiais.
\end{abstract}

\section{INTRODUÇÃO}

No contexto da expansão e intensificação de práticas extrativistas, as palmeiras são importantes fontes de recursos naturais nos países tropicais. Típica do cerrado brasileiro, a palmeira Macaúba (Acrocomia aculeata (Jacq.)Lodd. ex Mart) se encontra tradicionalmente atrelada ao extrativismo comunitário e é considerada a de maior dispersão no território nacional. Seu potencial econômico vem sendo enfatizado por gerações de pesquisadores, desde o início do século XVIII. Sua exploração, contudo, vem sendo realizada de forma ainda rudimentar e aquém de suas potencialidades comerciais e de introdução no cenário do agronegócio nacional (Pimenta, 2010; Caño Andrade, et al., 2006).

Perspectivas positivas para o processamento da Macaúba, inclusive no que se refere ao suprimento de grande parte da demanda nacional por óleos vegetais, indicam que o interesse em sua exploração supre expectativas e necessidades de setores industriais, dentre os quais o químico e alimentício. Atualmente, o setor alimentício responde pela maior parcela da demanda mundial e crescente de óleos vegetais. O interesse na Macaúba como alimento é abarcado, dentre outros fatores, pela qualidade nutricional de seus óleos na forma bruta. Apresentando elevado rendimento em óleo - até $18 \% \mathrm{~m} / \mathrm{m}$ de óleo no fruto fresco - o aproveitamento integral das polpas e amêndoas de seus frutos merece destaque (Pimenta, 2012; NEPA, 2011). 
Segundo projeto Brasil Food Trends 2020, lançado pela Federação das Indústrias do Estado de São Paulo - FIESP, juntamente com o Instituto de Tecnologia de Alimentos - ITAL, as exigências e tendências mundiais do mercado atual e futuro de alimentos vêm se modificando e podem ser agrupadas em cinco diferentes categorias: Sensorialidade e Prazer; Saudabilidade e Bem-estar; Conveniência e Praticidade; Confiabilidade e Qualidade; Sustentabilidade e Ética. A indústria brasileira indica a incorporação destas tendências nos hábitos de consumo de alimentos pela população. O mercado óleos vegetais e azeites também se mostra adepto das novas tendências, apresentando diversificação e agregação de valor em nichos ainda incipientes (Barbosa et al, 2010).

Alternativas gastronômicas de novos produtos alimentícios se relacionam aos termos gourmet ou especiais. Comparável aos óleos extraídos dos frutos da Macaúba, o desenvolvimento deste nicho do mercado de óleos e gorduras é observado para uma série de produtos, dentre os quais os produtos provenientes das seguintes matérias-primas: abóbora; macadâmia; argânia, pistache; alecrim; manjericão; orégano; menta; sementes do quiabo; sementes de nabo; farelos de arroz; sementes da uva; amendoim; babaçu, abacate; mostarda; gergelim, sementes da maçã, e framboesa (Codex Alimentarius, 2011; Paucar-Menacho, 2007; Freitas 2009).

\section{REVISÃO DE LITERATURA}

\subsection{Cenário Produtivo de Óleos Vegetais}

A produção mundial de oleaginosas tem apresentado incrementos significativos nos últimos anos. Particularmente na safra 2012/2013 produziram-se 462,99 milhões de toneladas de sementes, respectivamente. O Brasil contribuiu com $18 \%$ da produção mundial. Atualmente o país é o segundo maior produtor mundial de oleaginosas, após os Estados Unidos. As principais oleaginosas produzidas mundialmente na safra 2012/2013 (em milhões de toneladas métricas) foram: soja - 267; colza - 59; algodão - 44 (USDA, 2013).

Considerando a produção mundial de óleos vegetais na safra 2012/2013 (em milhões de toneladas métricas), destacam-se a: palma - 53; soja - 43; colza - 24; girassol - 14; amendoim 5; azeite de oliva - 3. A produção brasileira na safra 2012/2013 foi de 7,83 milhões de toneladas, ou 5\% da produção mundial. O consumo brasileiro de óleos vegetais na safra 2012/13 se aproximou de 6,60 milhões de toneladas. O valor representou 4,24 \% das 155,80 milhões de toneladas consumidas no mundo, e $84 \%$ da produção nacional. Atualmente o Brasil ocupa a sétima posição entre os maiores produtores de óleos vegetais, sendo a Indonésia o primeiro colocado (USDA, 2013).

O Brasil de destaca por ser o atual líder mundial na produção de grãos de soja. Na safra 2012/2013 o país contribuiu com 30\% da produção mundial. Apesar de a Macaúba contribuir para a produção brasileira de óleos vegetais com volumes de produção inferiores aos da soja, a oleaginosa detém maior potencial de fornecimento de óleo e biomassa por área plantada, até 6600 $\mathrm{kg}$ de óleo por hectare, frente aos $2.939 \mathrm{~kg}$ fornecidos pela soja. A maior parte da produção de óleos vegetais brasileiros se destina ao consumo alimentar (USDA, 2013; Pimenta, 2012).

O aumento da produção brasileira de óleos vegetais converge com índices mundiais de crescimento produtivo. A Lei Federal 11.097/2005 dispõe sobre a introdução de óleos na matriz energética brasileira e abre portas para a exploração de culturas oleaginosas com características 
nutracêuticas e apelos nutricionais. Ressalta-se que, por meio da Portaria $\mathrm{n}^{\circ} 1.156$, de 24 de Novembro de 2008, o Ministério da Agricultura Pecuária e Abastecimento apoia o mapeamento de macrorregiões, nas quais a Macaúba ocorre naturalmente, em favor da industrialização. Por meio da Lei $\mathrm{n}^{\circ}$ 19.485, de 13 de janeiro de 2011, o governo do Estado de Minas Gerais institui a política estadual de incentivo ao cultivo, extração, comercialização, consumo e transformação da Macaúba e palmeiras oleaginosas - "Pró-Macaúba" (Brasil, 2005a; Brasil, 2008; Brasil, 2011).

\subsection{Palmeira Macaúba}

A palmeira Macaúba (gênero Acrocomia) se distribui amplamente nas regiões da América Tropical, do Sul do Brasil ao sul do México, Argentina e Paraguai. Em território brasileiro a palmeira da espécie aculeata encontra melhores condições de rendimento em terras de cerrado, se concentrando nos estados de Minas Gerais, Goiás, Mato Grosso e Mato Grosso do Sul (Farias, 2010; Pimenta, 2012).

Em um hectare podem ser encontradas até 200 palmeiras na forma nativa, com produção próxima a 25 toneladas de cocos por ano - notória entre vegetais que, como a soja, são cultivados em solos brasileiros. O estádio ótimo de maturação destes frutos é verificado entre os meses de outubro e março - na prática, o ponto de colheita é identificado à medida que os frutos se soltam dos cachos, de forma intervalada. O contato eventual e prolongado dos frutos com o solo potencializa contaminações por flora microbiana e fungos produtores de enzimas lipolíticas, contribuindo com a liberação de ácidos graxos e consequente aumento da acidez dos óleos posteriormente extraídos (Farias, 2010; Caño Andrade et al.; 2006).

Os frutos maduros da Macaúba possuem formato esférico, com diâmetro variando entre 3,0 e $6,0 \mathrm{~cm}$. O epicarpo é rígido e quebradiço. Sob o epicarpo se encontra a polpa: amarelada, fibrosa, mucilaginosa, comestível, adocicada e rica em lipídeos e glicerídeos. A polpa envolve o endocarpo: de coloração marrom claro a escuro, duro, formado principalmente por lignina e holocelulose. O endocarpo envolve a amêndoa oleaginosa e proteica. Da massa total dos frutos da Macaúba, 24,1\% (m/m) são representados pela casca, 39,6\% (m/m) pela polpa, 29,0\% (m/m) pelo endocarpo e 7,3\% (m/m) pela amêndoa (Pimenta, 2010). Farias (2010) ressalta que a qualidade dos frutos da Macaúba e de seus derivados pode ser determinada pela associação de atributos, combinando fatores fisiológicos, como grau de desenvolvimento e amadurecimento, com os fatores físicos e químicos.

Conforme pode ser observado na Tabela 1, quando comparada à azeitona, o fruto fresco da Macaúba se destaca em conteúdo lipídico, bem como em fibras, minerais e vitaminas. É esperado que os óleos extraídos de seus frutos, quando comparados ao azeite de oliva, possuam, portanto, características nutricionais diferenciadas - o que justifica interesse ainda maior na exploração dos óleos da Acrocomia aculeata como produtos especiais para fins alimentícios (NEPA, 2011).

Carotenóides, tocoferóis, clorofila, dentre outros antioxidantes e corantes, são componentes com potencial nutracêutico presentes em porção minoritária na Macaúba. Tais componentes evidenciam os frutos como alimentos potencialmente benéfico e indispensável para a saúde humana. Citam-se como demais componentes minoritários presentes na porção oleica dos vegetais: vitaminas lipossolúveis A, D, E, K; proteínas; ácidos graxos livres, mono e diglicerídeos; fosfolipídeos; esteróis livres e esterificados (Pimenta, 2010). 
Tabela 1: Composição centesimal: parte comestível - Macaúba e Azeitonas

\begin{tabular}{|c|c|c|c|}
\hline $\begin{array}{c}\text { Componente } \\
\text { Teor/100g }\end{array}$ & $\begin{array}{l}\text { Macaúba } \\
\text { (100 g) }\end{array}$ & $\begin{array}{c}\text { Azeitona Verde } \\
(100 \mathrm{~g})\end{array}$ & $\begin{array}{c}\text { Azeitona Preta } \\
(100 \mathrm{~g})\end{array}$ \\
\hline Energia (Kcal) & 404 & 137 & 194 \\
\hline Umidade $(\%)$ & 41,5 & 76,3 & 68,5 \\
\hline Proteína (g) & 2,1 & 0,9 & 1,2 \\
\hline Lipídeos (g) & 40,7 & 14,2 & 20,3 \\
\hline Carboidrato(g) & 13,9 & 4,1 & 5,5 \\
\hline Fibra alimentar (g) & 13,4 & 3,8 & 4,6 \\
\hline Cinzas (g) & 1,8 & 4,5 & 4,5 \\
\hline Cálcio (mg) & 67 & 46 & 59 \\
\hline Magnésio (mg) & 66 & 4 & 5 \\
\hline Manganês (mg) & 0,08 & 0,03 & 0,06 \\
\hline Fósforo (mg) & 44 & 5 & 16 \\
\hline Ferro (mg) & 0,8 & 0,2 & 5,5 \\
\hline Sódio (mg) & 1,0 & 1347 & 1567 \\
\hline Potássio (mg) & 306 & 20 & 79 \\
\hline Cobre (mg) & 0,35 & 0,14 & 0,25 \\
\hline Zinco (mg) & 0,7 & 0,1 & 0,3 \\
\hline$R E(\mu \mathrm{g})^{*}$ & 1020 & - & - \\
\hline$R A E(\mu \mathrm{g})^{* *}$ & 510 & - & - \\
\hline Tiamina - B1 (mg) & 0,11 & Traços & Traços \\
\hline Riboflavina - B2 (mg) & 0,11 & Traços & Traços \\
\hline Piridoxina - B6 (mg) & 0,03 & Traços & 0,04 \\
\hline Niacina - B3 (mg) & Traços & Traços & Traços \\
\hline Ácido ascórbico - C (mg) & 13,4 & Traços & Traços \\
\hline
\end{tabular}

* RE (Equivalente de Retinol): retinol + beta-carotenos + carotenóides;

** RAE (Equivalente de Atividade de Retinol): retinol + beta-carotenos + carotenóides

FONTES: NEPA (2011); Amaya et al. (2011)

\section{3. Óleos e Gorduras}

Óleos e gorduras constituem fontes concentradas de energia e são essenciais para a dieta humana. Nos alimentos, atuam como agente transportador de calor. Conferem leveza a massas e também são veículos de aromas e sabor. Estas biomoléculas lipídicas são formadas predominantemente por ésteres, os triacilgliceróis. Possuem solubilidade elevada em solventes orgânicos e reduzida em água. Os ácidos graxos que compõe os triacilgliceróis são ácidos carboxílicos com cadeias de hidrocarbonetos, contendo de 4 a 36 átomos de carbono em suas estruturas - podem ser saturados, monoinsaturados ou poliinsaturados (Hartman e Esteves, 1982).

Óleos extraídos da amêndoa e da polpa dos frutos da Macaúba: Em base seca, os teores de óleo nos frutos da Macaúba são ligeiramente mais elevados na amêndoa (55-60\%) em relação à polpa (50-55\%) (Pimenta et. al 2012). Da amêndoa extrai-se um óleo fino e saboroso, com coloração que varia de branca a amarela translúcida, sendo popularmente, porém erroneamente, comparável ao azeite de oliva pelo seu uso destinado a alimentação. O óleo extraído da polpa 
possui coloração amarelada a avermelhada, atribuída à presença de carotenoides. Na Tabela 2 é possível observar que o óleo da polpa apresenta predominância de ácidos graxos insaturados. Suas características são favoráveis ao processamento industrial, exigindo atenção quanto à susceptibilidade à degradação de sua qualidade (Farias, 2010).

Tabela 2: perfil graxo de óleos e azeites: Macaúba, Dendê, Oliva, e bagaço de Oliva

\begin{tabular}{ccccccc}
\hline & \multicolumn{2}{c}{ Macaúba } & Dendê & \multicolumn{3}{c}{ Oliva } \\
\cline { 2 - 7 } Ácidos Graxos & Amêndoa & Polpa & Azeite & $\begin{array}{c}\text { Azeite } \\
\text { Virgem }\end{array}$ & $\begin{array}{c}\text { Azeite } \\
\text { Refinado }\end{array}$ & $\begin{array}{c}\text { Bagaço } \\
\text { Refinado }\end{array}$ \\
\hline Caprílico C8:0 & 4,15 & - & - & - & - & - \\
Cáprico C10:0 & 4,22 & - & - & - & - & - \\
Láurico C12:0 & 41,42 & - & $<0,4$ & - & - & - \\
n-tridecílico C13:0 & 0,03 & - & - & - & - & - \\
Mirístico C14:0 & 7,89 & 0,03 & $0,5-2,0$ & $0,0-0,05$ & $0,0-0,05$ & $0,0-0,05$ \\
Palmítico C16:0 & 5,98 & 16,51 & $35-47$ & $7,5-20,0$ & $7,5-20,0$ & $7,5-20,0$ \\
Palmitoléico C16:1 & -- & 2,92 & $<0,6$ & $0,3-3,5$ & $0,3-3,5$ & $0,3-3,5$ \\
Margárico C17:0 & -- & 0,05 & - & $0,0-0,3$ & $0,0-0,3$ & $0,0-0,3$ \\
Miristoléico C17:1 & -- & 0,08 & - & $0,0-0,3$ & $0,0-0,3$ & $0,0-0,3$ \\
Esteárico C18:0 & 3,38 & 2,89 & $3,5-6,5$ & $0,5-5,0$ & $0,5-5,0$ & $0,5-5,0$ \\
Oléico C18:1 & 29,22 & 67,67 & $36-47$ & $55-83$ & $55-83$ & $55-83$ \\
Linoléico C18:2 & 3,43 & 8,82 & $6,5-15,0$ & $3,5-21,0$ & $3,5-21,0$ & $3,5-21,0$ \\
Linolênico C18:3 & -- & 0,81 & $<0,5$ & - & - & - \\
Araquídico C20:0 & 0,14 & 0,16 & $<1,0$ & $0,0-0,6$ & $0,0-0,6$ & $0,0-0,6$ \\
Eicosenóico C20:1 & - & - & - & $0,0-0,4$ & $0,0-0,4$ & $0,0-0,4$ \\
Behênico C22:0 & - & - & - & $0,0-0,2$ & $0,0-0,2$ & $0,0-0,3$ \\
Lignocérico C24:0 & - & - & & $0,0-0,2$ & $0,0-0,2$ & $0,0-0,2$ \\
C18:1 T & - & - & - & $0,0-0,05$ & $0,0-0,20$ & $0,0-0,40$ \\
C18:2 T + C18:3 T & - & - & $0,0-0,05$ & $0,0-0,30$ & $0,0-0,35$ & - \\
\hline
\end{tabular}

FONTES: CODEX (2009); Pimenta et al. (2012); Brasil (1999)

De acordo com a Tabela 2, no que se refere ao percentual de saturação e perfil graxo, verifica-se que o azeite de oliva apresenta maior semelhança com o óleo da polpa - rico em rico em insaturados. O Ministério da Saúde define ácidos graxos insaturados como benéficos à saúde e descreve os óleos vegetais como fontes principais de monoinsaturados, a exemplo do ácido oleico $(\omega$ 9). Alguns ácidos graxos poliinsaturados são essenciais para manutenção da saúde humana, como o ácido linolênico ( $\omega$ 3) e o ácido linoleico ( $\omega$ 6) (Pimenta, 2012).

Caño Andrade e colaboradores (2006) ressaltam a importância das pesquisas que objetivem o desenvolvimento de processos e produtos com valores agregados, visando desenvolver o potencial de aproveitamento dos óleos da Macaúba. Freitas et al. (2009) demonstram a relevância da elaboração de Blends oléicos alimentícios, atreláveis também aos óleos dos frutos da Macaúba, como forma de unir componentes e de contribuir com desenvolvimento científico e tecnológico.

Quanto ao tema caracterização dos frutos e dos óleos da Macaúba, observam-se na literatura divergência entre dados publicados. Estudos conclusivos são dependentes, entre outros fatores, da origem dos frutos, do tempo decorrido entre a colheita e o processamento, do tipo de 
processamento, do período entre este processamento e os ensaios laboratoriais, bem como da padronização de metodologias e da homogeneidade dos graus de umidade e de maturidade dos frutos submetidos às análises. A confiabilidade de resultados analíticos, portanto, depende da utilização de amostras que representem lotes de frutos frescos e recém-colhidos, e se faz necessária para a tomada de ações que preencham lacunas científicas, tecnológicas e industriais. No entanto, é consenso a partir da análise de dados da literatura, que a Macaúba possui potencial para a produção de óleos em escala comercial e com elevada qualidade nutricional (Caño Andrade et al. 2006; Rettore \& Martins 1983; Farias 2010).

\subsection{Processamento de óleos vegetais}

Óleos vegetais comestíveis são obtidos, basicamente, por meio das seguintes etapas de processamento: extração de óleo bruto da matriz oleaginosa e refino. A extração dos óleos pode ocorrer por meio de um dos processos a seguir, isolados ou combinados: prensagem mecânica e extração por solventes. A aplicação de solventes na extração de óleos vegetais, visando rendimento, requer etapas posteriores de refino e contribui com incrementos no custo do processo e influencias na qualidade sensorial e nutricional do óleo. O refino de óleos vegetais envolve etapas como degomagem, desacidificação (química ou física), clarificação e desodorização. (Farias, 2010; Hartman e Esteves, 1982).

Vários parâmetros influenciam o rendimento da extração durante a prensagem. Prétratamentos aplicados à matéria-prima, teor de umidade, temperatura de extração e pressão aplicada pela prensa são fatores que podem ser controlados (Pimenta, 2010). Farias (2010) avaliou o armazenamento e o processo de extração dos óleos extraídos da polpa e da amêndoa do fruto da Macaúba por prensagem mecânica (temperatura extração $\leq 85^{\circ} \mathrm{C}$ ). Foram verificados índices de acides e de peróxido reduzidos, e a possibilidade de extração dos óleos de Macaúba com qualidade alimentícia.

Novas tecnologias envolvendo o preparo da matéria-prima têm sido desenvolvidas, contribuindo para o aumento de rendimento no processamento e na preservação da qualidade sensorial e nutricional de óleos vegetais. Silva et al. (2008) verificaram efeitos positivos da combinação de tecnologia enzimática e prensagem hidráulica na extração do óleo da polpa da Macaúba. Da Silva (2009) propõe um processo tecnológico sustentável para a obtenção de óleo da polpa da Macaúba, combinando tratamento térmico com vapor, secagem por micro-ondas e hidrólise enzimática - a adição de enzimas aumentou o rendimento preservando a qualidade.

Visando a obtenção de óleos diferenciados, a extração mecânica tem sido aplicada com base no processamento aplicado a algumas culturas oleaginosas. Principalmente quando conduzida a baixas temperaturas, tal extração produz óleos brutos que, tal qual o óleo da oliva, apresentam qualidade que dispensam etapas de refino. Trabalhos apontam a Macaúba como fonte de óleos brutos que dispensam processos adicionais para consumo humano. A possibilidade de combinar as características físico-químicas da Macaúba com processamentos eficientes e brandos amplifica o interesse em sua exploração para a obtenção de óleos pouco processados e que aderem a novos nichos de mercado, com componentes nutricionais preservados (Farias, 2010; Pimenta, 2010).

Segurança e Legislações para Alimentos: Atualmente, em função da inexistência de diretrizes específicas para a cultura da Macaúba, referências estabelecidas para alimentos similares aos seus coprodutos devem ser pra ela adotadas. A demanda pela padronização e normatização de 
procedimentos relacionados à Acrocomia aculeata tem surgindo no mesmo sentido, crescente, do interesse comercial e industrial de exploração da palmeira. Ressalta-se a importância de as legislações nacionais serem compatibilizadas de forma preferencialmente harmonizada com regulamentos internacionais, incluindo-se o Mercosul. A garantia da qualidade biológica, sanitária, nutricional e tecnológica dos alimentos é definida pelo governo brasileiro por meio da Lei $\mathrm{N}^{\circ}$ 11.346, de 15 de setembro de 2006 (Brasil, 2006a; Pimenta, 2010).

Exemplos de diretrizes compatíveis com a cultura Macaúba incluem: MAPA IN no 49, de 22 de dezembro de 2006 - aprova o Regulamento Técnico de Identidade e Qualidade para óleos vegetais refinados; ANVISA RDC n ${ }^{\circ} 12$, de 2 de janeiro de 2001 - aprova o Regulamento Técnico sobre padrões microbiológicos para alimentos destinados ao consumo humano; ANVISA RDC $\mathrm{n}^{\circ}$ 270, de 22 de setembro de 2005 - aprova o Regulamento Técnico de Identidade e Qualidade para óleos, gorduras e creme vegetal. Norma CODEX STAN 210-1999 - aplicável a óleos vegetais destinados ao consumo humano; Norma CODEX STAN 33-1981 - aplicável a azeites de oliva e a óleos de bagaço de azeitona (CODEX ALIMENTARIUS, 2011; Brasil, 2001; Brasil, 2002; Brasil, 2005b; Brasil, 2006b).

\section{CONSIDERAÇÕES FINAIS}

O levantamento bibliográfico apresentado incide sobre o potencial de exploração comercial da cultura Macaúba, com viabilidade de sua utilização como matéria-prima em larga escala. Embasa-se o potencial da produção de seus óleos, priorizando características especiais. Sendo assim, como forma de assegurar processos e produtos com qualidade, ressalta-se a necessidade de se somarem esforços e ações nas esferas tecnológica, científica, industrial e governamental.

\section{REFERÊNCIAS}

AMAYA-FARFÁN, J.; RODRIGUEZ-AMAYA, D.B.; NOLETO CRUZ, P.; MARQUES, E.P. Fatty acid and amino acid composition of some indigenous fruits of northeastern Brazil. Revista Ciência e Tecnologia de Alimentos. Campinas, v.6, p.86-92, 1986.

BARBOSA, L.; MADI, L.; TOLEDO, M. A.; REGO, R. A. Brasil Food Trends 2020. Federação das Indústrias do Estado de São Paulo - FIESP. ITAL. São Paulo, v.1, n.1, p. 39-47, 2010.

BRASIL. Diretoria Colegiada da ANVISA. Resolução RDC n 12, de 02 de janeiro de 2001. Diário Oficial da União. Brasília, 12 de janeiro de 2001.

BRASIL. Diretoria Colegiada da ANVISA. Resolução RDC n ${ }^{\circ}$ 275, de 21 de outubro de 2002. Diário Oficial da União 206. Brasília, p.126, 23 de outubro de 2002.

BRASIL. Diretoria Colegiada da ANVISA. Resolução RDC no 482, de 23 de setembro de 1999. Diário Oficial da União. Brasília, Seção 1, p.82-87, 13 de outubro de 1999.

BRASIL. Conselho Nacional de Segurança Alimentar e Nutricional. Lei No 11.346 de 15 de setembro de 2006. Diário Oficial da União. Brasília, p. 1, seção 1, 18 de set. 2006.

BRASIL. Casa Civil. Subchefia para Assuntos Jurídicos. Lei n ${ }^{\circ} 11.097$, de 13 de Janeiro de 2005. Diário Oficial da União. Brasília, v.1, p.1, 14 de janeiro de 2005.

BRASIL. Governo do Estado de Minas Gerais. Lei № 19.485 de 13 de janeiro de 2001. Diário Oficial do Estado de Minas Gerais. Belo Horizonte, n.9, p.2, 14 de janeiro 2011. 
BRASIL. Ministério da Agricultura, Pecuária e Abastecimento. Instrução Normativa ${ }^{\circ}$ 49, de 22 de Dezembro de 2006. Diário Oficial da União. Brasília, Seção 1, 26 de dezembro de 2006.

BRASIL. Ministério da Agricultura, Pecuária e Abastecimento. Portaria $\mathrm{n}^{\circ} 1.156$, de 24 de Novembro de 2008. Diário Oficial da União. Brasília, Seção 1, 26 de Novembro de 2008.

BRASIL. Ministério da Saúde. ANVISA. Resolução RDC no 270, de 22 de setembro de 2005. Diário Oficial da União. Brasília, p.1, 23 de setembro de 2005.

CAÑO ANDRADE, M. H.; VIEIRA, A. S.; AGUIAR, H. F.; CHAVES, J. F. N.; Neves, R.M.P.S.; MIRANDA, T. L. S.; SALUM, A. Óleo do Fruto da Palmeira Macaúba Parte I: Uma Aplicação Potencial Para Indústrias de Alimentos, Fármacos e Cósmeticos. In: Anais do II ENBTEQ / III Seminário ABIQUIM de Tecnologia. São Paulo: v. 1. p.1, 2006.

CODEX ALIMENTARIUS (FAO/WHO). Codex Standard for Named Vegetable Oils. CODEX STAN 210 -1999. Codex Alimentarius, Roma, Itália, rev. 3, amend. 2. 2011.

DA SILVA, I. C. C. Uso de Processos Combinados Para Aumento Do Rendimento da Extração e da Qualidade do Óleo de Macaúba. Escola de Química. Rio de Janeiro, Universidade Federal do Rio de Janeiro. Rio de Janeiro, v.1, n.1, p.99, 2009.

FARIAS, T. M. Biometria e processamento dos frutos da macaúba (Acrocomia sp) para a produção de óleos. FEQ - EE - UFMG. Belo Horizonte, MG. Brasil. v.1, n.1, p.93, 2010

FREITAS, L. R.; JUNIOR, F. B. P.; ROCHA, H. G. DE SOUSA, S. A.; ALVES, S. B. Caracterização físico-química e toxicológica do óleo de soja, do óleo composto (soja + algodão). Revista CIENTEC. Recife, v.1, n.1, p.25-38, 2009.

HARTMAN, L.; ESTEVES, W. Tecnologia de óleos e gorduras vegetais. Série Tecnologia Agroindustrial. São Paulo. Secretaria da Indústria e Comércio. n.13, 1982.

NEPA - Núcleo de Estudos e Pesquisas em Alimentação. Universidade Estadual de Campinas. TACO - Tabela Brasileira de Composição de Alimentos. Campinas, v.1, p.161, 2011.

PAUCAR-MENACHO, Luz Maria et al . Refino de óleo de farelo de arroz (Oryza sativa L.) em condições brandas para preservação do $\gamma$-orizanol. Revista Ciência e Tecnologia de Alimentos, Campinas, n.1, v.27, p.45-53, 2007.

PIMENTA, T. V. Metodologias de Obtenção e Caracterização dos Óleos do Fruto da Macaúba com Qualidade Alimentícia: Da coleta à utilização. Escola de Engenharia. Departamento de Engenharia Química. UFMG. Belo Horizonte, MG. Brasil. v.1, p.102, 2010.

PIMENTA, T. V.; ANDRADE, M. H. C.; ANTONIASSI, R. Extração, Neutralização $e$ Caracterização dos Óleos do Fruto da Macaúba (Acrocomia Aculeata). In: XIX Congresso Brasileiro de Engenharia Química, 2012 - UFRJ. Rio de Janeiro, v.1, p.4031-4040, 2012.

RETTORE, R. P.; MARTINS, H. Produção de combustíveis líquidos a partir de óleos vegetais: Estudo das oleaginosas nativas de Minas Gerais. Projeto da Fundação Centro Tecnológico de Minas Gerais - CETEC, Belo Horizonte, v.1. 1983.

SILVA, I. C. C.; PONTES, F.S; COURI, S.; ARAUJO, M. M.; FREITAS, S. P. Extração combinada do Óleo de macaúba: tecnologia enzimática e prensagem hidráulica. In: $5^{\circ}$ Congresso Nacional de Plantas Oleaginosas, Óleos, Gorduras e Biodiesel. UFLA-MG. Lavras, p.1-10, 2008.

USDA - United States Department of Agriculture. FAS. Office of Global Analysis. Oilseeds: World Markets and Trade. Circular Series. Washington, DC. v.1, n.13-01, p.33, 2013. 